\title{
Intraspecific convergence of floral size correlates with pollinator size on different mountains: a case study of a bumblebee-pollinated Lamium (Lamiaceae) flowers in Japan
}

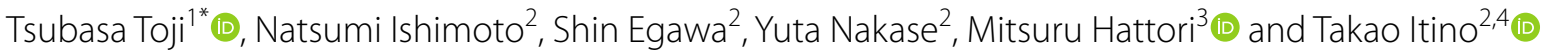

\begin{abstract}
Background: Geographic differences in floral size sometimes reflect geographic differences in pollinator size. However, we know little about whether this floral size specialization to the regional pollinator size occurred independently at many places or occurred once and then spread across the distribution range of the plant species.

Results: We investigated the relationship between the local floral size of flowers and local pollinator size in 12 populations of Lamium album var. barbatum on two different mountains in the Japan Alps. Then, using 10 microsatellite markers, we analyzed genetic differentiation among the 12 populations. The results showed that local floral size was correlated with the average size of relevant morphological traits of the local pollinators: floral size was greater in populations visited frequently by the largest flower visitors, Bombus consobrinus queens, than it was in other populations. We also found that the degree of genetic similarity between populations more closely reflected interpopulation geographic proximity than interpopulation similarity in floral size.

Conclusions: Although genetic similarity of populations was highly associated with geographic proximity, floral size varied independently of geographic proximity and was associated with local pollinator size. These results suggest that in L. album var. barbatum, large floral size evolved independently in populations on different mountains as a convergent adaptation to locally abundant large bumblebee species.
\end{abstract}

Keywords: Bumblebee, Flower size, Independent evolution, Pollination, Trait matching

\section{Background}

Plant-pollinator interaction, one of the main mutualistic relationships between angiosperms and animals, greatly influences the reproductive success of plants [1-7]. Floral adaptation to pollinators is thought to be a key mechanism leading to the diversification of flower traits and

\footnotetext{
*Correspondence: tsubasa.toji@gmail.com

${ }^{1}$ Graduate School of Medicine, Science and Technology, Shinshu

University, Matsumoto, 3-1-1 Asahi, Nagano 390-8621, Japan
}

Full list of author information is available at the end of the article speciation in angiosperms [8-11]. Accordingly, variations in floral characteristics, including in flower shape [12, 13], size $[14,15]$, color $[16,17]$, and odor $[18,19]$, have been recognized to have resulted from adaptation to pollinators. In fact, many studies have shown that geographic variation of flower traits is associated with geographic variation of pollinator assemblages [4, 13, 20-32]. These have been interpreted as the consequences of adaptation of floral traits to pollinators. 
Local adaptation of plants to pollinators can lead to plant speciation through the establishment of prezygotic reproductive isolation, because specialization to specific pollinators may preclude pollinator sharing between related plant lineages [4, 22, 33]. In fact, according to the Grant-Stebbins model of floral divergence $[8,9,11$, 34], prezygotic reproductive isolation through pollinator-based selection is the main pathway of floral trait diversification. The Grant-Stebbins model proposes that local adaptation of plants to local pollinator assemblages results in trait diversification and reinforcement of reproductive isolation. Thus, a geographic mosaic of flower visitors may promote allopatric divergence of plants leading to the emergence of different ecotypes. Accordingly, if divergence in allopatry is followed by secondary contact, we can hypothesize that local adaptation to pollinators may prevent gene flow between the two ecotypes even after the secondary contact $[18,19]$. One useful approach to understanding trait diversification and speciation in angiosperms, therefore, is to combine an ecological evolutionary analysis of local plant adaptations with an analysis of population genetics to assess the degree of genetic isolation between populations. Given that about $25 \%$ of angiosperm diversification events may be associated with a shift in pollinators [35], this combination of analytical approaches can shed considerable light on the origin of plant diversity $[36,37]$. Nevertheless, researchers focusing on plant diversification have only recently begun to use these two approaches in combination [34, 38, 39]. In particular, knowledge of the patterns of morphological changes associated with intraspecific genetic structures can contribute to our understanding of the early stages of divergence [34].

In this study, we posit two hypotheses to explain geographic differences in floral characteristics. The first hypothesis is 'secondary contact' hypothesis. It assumes that allopatric floral size differentiation occurred between populations with large-sized flowers where plants were pollinated by large pollinators, and populations with small-sized flowers where plants were pollinated by small pollinators. In this scenario, the different-sized flowers have already been reproductively isolated because of the different pollinators, their distribution range secondarily overlapped, and currently gene flow occurs only between similar-sized flowers. The second hypothesis is 'independent local adaptation of floral size.' In contrast to 'secondary contact' hypothesis, it assumes that the local floral size is the results of current adaptation selected by local pollinator size and the gene flow occurs mainly between nearby populations because no reproductive isolation between different-sized flowers evolved yet. In this scenario, the degree of genetic similarity among populations should reflect geographic proximity rather than floral size similarity. Based on this hypothesis, we assume that the floral size has evolved independently among mountain regions.

Lamium album (Lamiaceae) is native to Europe and Asia. In Europe, it is reported to be visited mainly by bumblebees, small wild bees and honeybees [40]. The Asian subspecies, L. album var. barbatum, is visited mainly by bumblebees [41]. In Japan, floral size varies geographically in Lamium album var. barbatum [41]. Flower-pollinator trait matching has been demonstrated in a Japanese population of L. album var. barbatum by Hattori et al. [42], who observed that as the difference between bumblebee tongue length and the floral size of L. album var. barbatum becomes larger in a population, fruit set per single pollinator visit becomes smaller. Thus, we expect floral size to be greater in Japanese populations of $L$. album var. barbatum visited by larger pollinators, and we can expect to find a relationship between floral size and the size of relevant pollinator traits in those populations.

In this study, we investigated the relationship between floral size and pollinator size in 12 populations of $L$. album var. barbatum in two different mountain areas and confirmed plant-pollinator trait matching in these populations: plants in populations visited by long-tongued pollinators characteristically had long corolla tubes, whereas plants in populations visited by short-tongued pollinators had short corolla tubes. In addition, using 10 microsatellite markers, we estimated the population genetic structures of the $12 \mathrm{~L}$. album var. barbatum populations and found that floral size correlated with local pollinator size but not with the genetic similarity of populations. This finding supports convergent intraspecific floral trait evolution: the second of the two hypotheses formulated above.

\section{Results}

\section{Geographic variation of floral size}

We found that floral size of L. album var. barbatum and the pollinator assemblage greatly differed among populations (Tukey's HSD, $P<0.05$; Table 1). There was no spatial autocorrelation of average floral size between populations (Moran's $I=-0.028 ; P=0.332$ ).

\section{Pollinator size variation}

In the survey of insect visitors, large bees, small bees (whole-body pollinators), small bees (without attached pollen grains), and nectar robbers were observed (Additional file 1: Table S1). In particular, only small bees visited flowers of the Shimashima I population. In contrast, only large bees visited flowers of the Ougisawa and Hirokoba populations. In our analysis, we treated only the first two groups as valid pollinators. 
Toji et al. BMCEcol Evo $\quad$ (2021) 21:64

Page 3 of 13

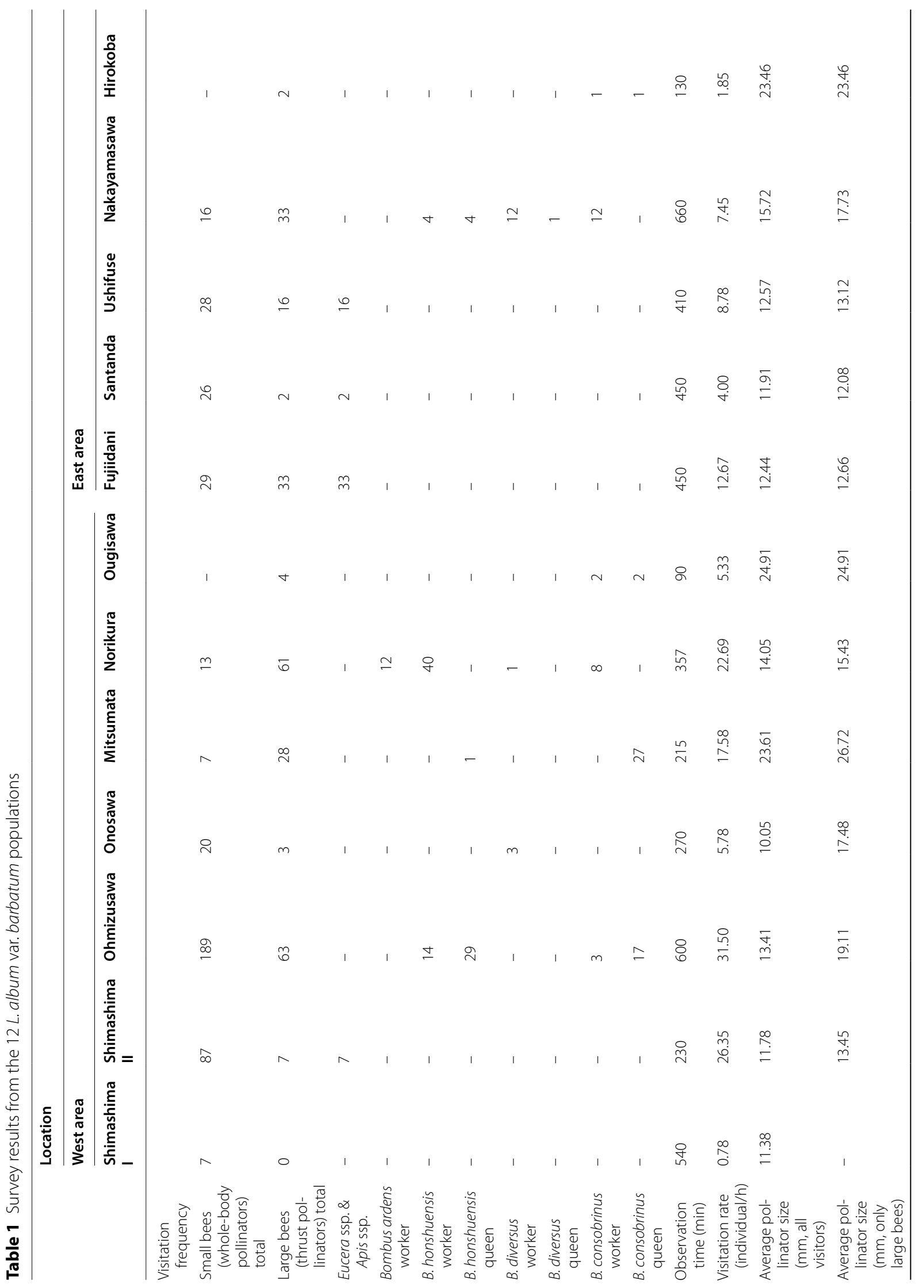




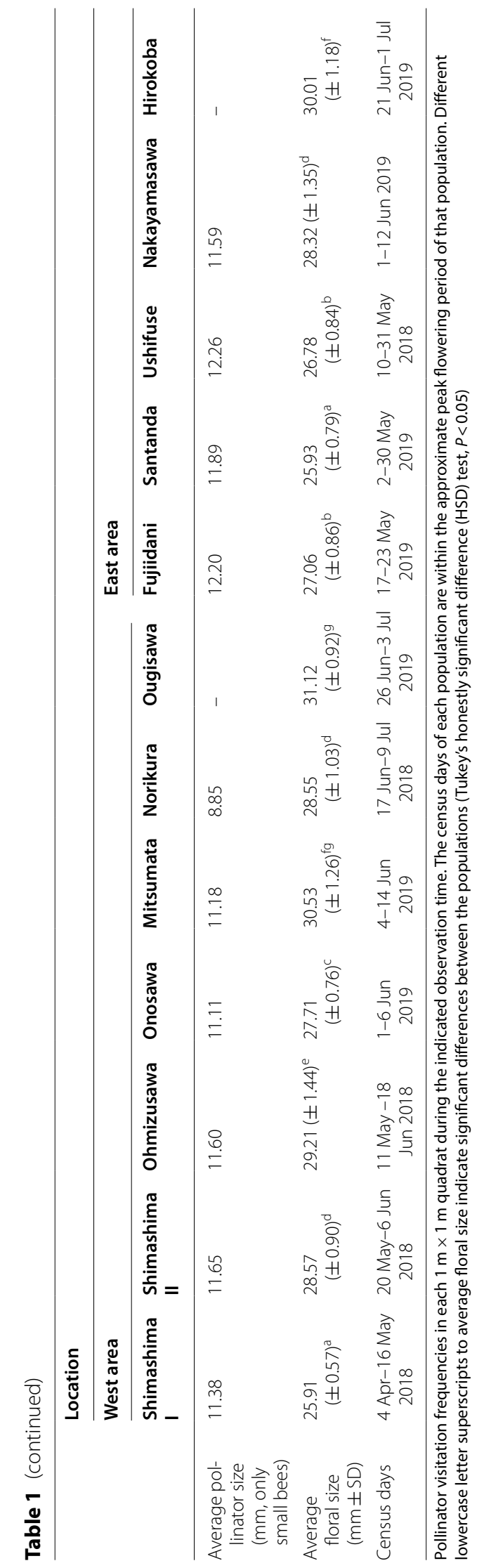


The average pollinator size varied among populations: for all pollinators (first two groups only), it was 10.05$24.91 \mathrm{~mm}$; for large bees, it was $12.08-26.72 \mathrm{~mm}$, and for small bees, it was 8.85-12.26 mm (Table 1). The largest bees were queens of Bombus consobrinus, which were observed in particularly high proportions in the Mitsumata, Ougisawa, and Hirokoba populations (Additional file 1: Table S1). Bees that were not considered to contribute to pollination were excluded from the size measurements. These included small bees without attached pollen grains (E. nipanicus, $L$. nipponense, L. occidens, $N$. comparata, and Nomada spp.), which were observed only at Onosawa and Fujiidani, and nectar robbers (A. mellifera, B. hypocrita, X. appendiculata circumvolans), which forage for nectar by drilling a hole in the lower part of the corolla tube (Additional file 1: Table S1).

\section{Factors influencing local floral size}

As a variable selection result, average pollinator size (only small bees) and plant height were selected as ineffective variables, so these variables were excluded from LMM analysis (Likelihood ratio test, $P<0.01$ ). The model with the lowest Akaike information criterion (AIC) value and occupied high weight was that in which the average pollinator size (only large bees) was included as only predictive variable (Additional file 2: Table S2). In this model, the average pollinator size (only large bees) was a statistically significant variable (Table 2). By a regression analysis between floral size and the average pollinator size (only large bees), we detected a strong relationship (least squares regression, $R^{2}=0.807$, LMM, $P<0.001$; Fig. 1 ).

\section{Genetic structure of Lamium album var. barbatum populations}

The analysis of molecular variance (AMOVA) result based on 10 microsatellite loci also indicated a significant difference in genetic structure between the two mountain areas (Table $3 ; \Phi_{\mathrm{CT}}=0.031 ; P<0.022$ ). However, in the AMOVA result, most of the genetic variation was detected within populations $(79.56 \%)$ and among populations within areas (17.31\%). In the STRUCTURE analysis result, the most appropriate number of genetic clusters was $K=2$ (Fig. 2a), and, for the most part, the populations in the east area were found to differ genetically from those in the west area (Fig. 2b). However, the Shimashima I population, although located in the west area, was genetically closer to populations in the east area, whereas the Fujiidani population, which was in the east area, was genetically closer to populations in the west area.

\section{Discussion}

Relationship between floral size and pollinator size

Both the floral size and pollinator assemblages of $L$. album var. barbatum showed geographic variations (Table 1; Fig. 3), but the lack of any spatial autocorrelation of floral size suggests that populations that are spatially close are not necessarily similar in floral size. In fact, the model that best explained floral size of a population was that in which the average size of large bees was the only explanatory variable (Table 2). Moreover, in the regression analysis of the 12 populations, floral size was strongly correlated with the average size of large bee pollinators (Fig. 1).

Unlike large bees, small bees can forage successfully in flowers with both short and long corolla tubes because they crawl into the flower tube to forage. Therefore, a match between the body size of small bees and floral size is not necessary for successful pollination. Interspecific variation in body size and tongue length is a prominent feature of large bees, Bombus spp., and many studies have demonstrated correlations between floral size in a plant species and the Bombus species composition of its pollinator assemblage $[3,13,31,43]$. Our results indicate that in L. album var. barbatum, floral size at a particular location is correlated with the local average body size of large bees. However, it is possible that the correlation between floral size and local pollinator size reflects selection on a co-varying characteristic or selection mediated by other agents [44]. In this context, the observation that the correlation between floral size and local pollinator size was associated with seed set per single visit by a bumblebee in a L. album var. barbatum population at Norikura [42] is good evidence that variation in this floral trait represents an adaptation to pollinator size.

At the Mitsumata and Hirokoba locations, the herb Meehania urticifolia, which has a long corolla tube (over $40 \mathrm{~mm}$ ), was abundant, and B. consobrinus queens visited the flowers of this herb during its flowering season, just prior to that of L. album var. barbatum. Similarly, at Ougisawa, the shrub Weigela hortensis, which also has a long corolla tube, blooms a little earlier than L. album var. barbatum, and B. consobrinus queens were observed to visit flowers of both species ( $\mathrm{T}$. Toji personal observation). Thus, at sites with populations of L. album var. barbatum flowers having long corolla tubes, other flower species also tended to have long corolla tubes. These observations suggest that the local evolution of long floral size in L. album var. barbatum may reflect interactions with large bumblebees in these local areas.

Our results add to this classic flower-pollinator trait matching result $[4,13,20-32]$, and we show that the selection by flower visitors is the evolutionary background of change in floral size (Fig. 1). The mechanism 
Table 2 Outcome of the linear mixed model with the lowest AIC value (Additional file 2: Table S2)

\begin{tabular}{lllll}
\hline Factor & Coefficient & SE & $\boldsymbol{t}$ & $\boldsymbol{P}$-value \\
\hline Intercept & 23.07 & 0.532 & 43.39 & 0.009 \\
$\begin{array}{l}\text { average pollinator } \\
\text { size (only large } \\
\text { bees) }(\mathrm{mm})\end{array}$ & $3.076 \times 10^{-1}$ & $8.031 \times 10^{-3}$ & 38.31 & $2.00 \times 10^{-16}$ \\
\hline
\end{tabular}

Testing the effect of the average pollinator size (only large bees) to floral size of L. album var. barbatum

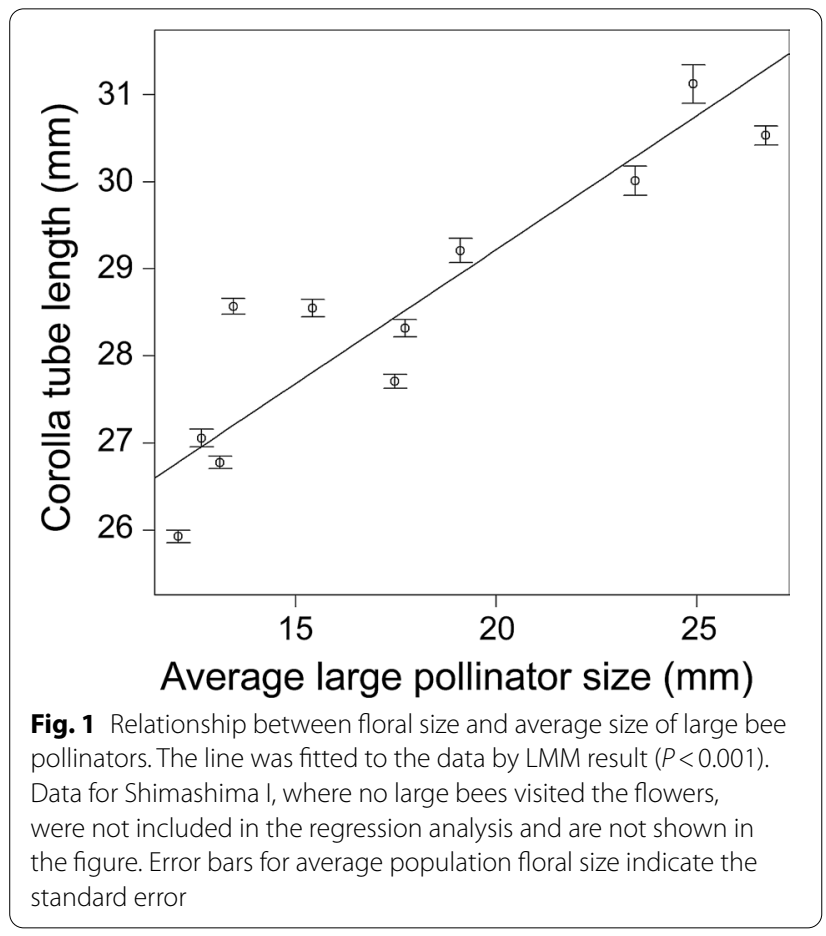

through which pollinators exert the selective pressures have been shown to be selection in pollen export. A recent meta-analysis has shown that the amount of investment in petals evolves via strong competition for pollen export [45]. It is conceivable that this complex of factors may have resulted in selection for floral size.
However, the very strong linear relationship between floral size and pollinator size still suggests that selection by flower visitors is the evolutionary background of floral size (Fig. 1).

\section{Genetic structure and independent floral size adaptation}

The STRUCTURE analysis and AMOVA results suggest that, in general, populations within each mountain area were more closely related to each other than they were to populations in the other mountain area (Table 3; Fig. 2; Additional file 3: Figure S1). The largest flower visitors, B. consobrinus queens, visited four populations, Ohmizusawa, Mitsumata and Ougisawa in the west area and Hirokoba in the east area, and floral size in these four populations was significantly longer than it was in other populations (Table 1). However, in the genetic clustering analysis results, Ohmizusawa, Mitsumata and Ougisawa belonged to one of the two genetic clusters detected whereas Hirokoba belonged to the other (Fig. 2). This result suggests that floral size in L. album var. barbatum evolved independently in each genetic cluster.

The large genetic gap between the Shimashima I and Shimashima II populations is interesting because these two populations are only $0.4 \mathrm{~km}$ apart in straight line distance (Fig. 3). This genetic difference may reflect a history of colonization. In these two populations, $L$. album var. barbatum plants bloom at different times of the year (Table 1), and the pollinator assemblages and floral size distributions also differ between them. Given these differences in the timing of flowering and in the flower visitor assemblages, we infer that these populations are able to maintain genetic independence despite their proximity. Similarly, in Matsumoto, Japan, the shrub Cimicifuga simplex comprises multiple parapatric ecotypes that appear to be maintained by differences in the flowering season and flower visitor assemblage among the ecotypes $[18,46]$. Further study is needed to determine what factors maintain the genetic differentiation between the Shimashima I and II populations in L. album var. barbatum. Although Shimashima I is located in the west area, it is genetically more closely related to populations in the east area.

Table 3 Analysis of molecular variance (AMOVA) results for the 12 L. album var. barbatum populations

\begin{tabular}{|c|c|c|c|c|c|}
\hline Source of variance & df & SS & Variation (\%) & $\Phi$ statistic & $p$-value \\
\hline Among mountain areas: west and east area & 1 & 34.52 & 3.13 & $\Phi_{C T}=0.031$ & 0.022 \\
\hline Among populations within areas & 10 & 170.24 & 17.31 & $\Phi_{\mathrm{SC}}=0.179$ & $<0.001$ \\
\hline Within populations & 494 & 832.75 & 79.56 & $\Phi_{\mathrm{ST}}=0.204$ & $<0.001$ \\
\hline Among floral size groups: based on Tukey's HSD & 5 & 92.231 & -1.10 & $\Phi_{C T}=-0.001$ & 0.621 \\
\hline Among populations within floral size groups & 6 & 112.528 & 20.28 & $\Phi_{S C}=0.201$ & $<0.001$ \\
\hline Within populations & 494 & 832.749 & 80.81 & $\Phi_{\mathrm{ST}}=0.192$ & $<0.001$ \\
\hline
\end{tabular}



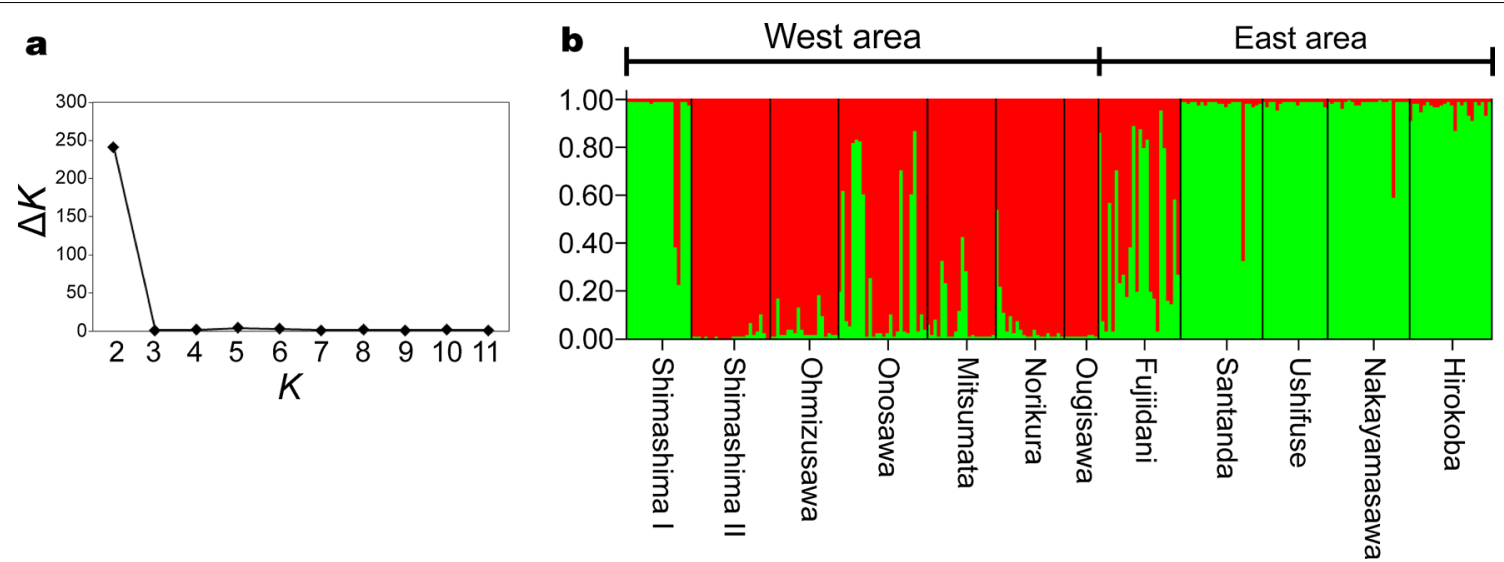

Fig. 2 Population genetic structure of $L$. album var. barbatum populations. a $\triangle K$, an index used to determine the appropriate number of genetic clusters (K), peaked at $K=2$. b Genetic structure of $L$. album var. barbatum inferred by using Bayesian clustering implemented in STRUCTURE with $K=2$. Different genetic clusters are represented by different colors

Similarly, Fujiidani is in the east area but is genetically more closely related to populations in the west area (Fig. 2b). Clear evidence to explain these discrepancies in the genetic structure of these populations is currently lacking.

The most striking aspect of our results is that the evolutionary geographic mosaic displayed by flower tube length variation reflects the regional distribution of the large bumblebee $B$. consobrinus, whereas the genetic similarity among populations reflects geographic proximity rather than flower trait similarity. Our results thus support the second hypothesis (floral size ecotypic 'speciation' did not occur, and trait divergence is independent of population genetic structure: convergent intraspecific floral trait evolution) proposed in the introduction. Sympatric ecotypic divergence in different mountain areas in Japan has also been reported in the alpine herb Potentilla matsumurae [47]. In this species, two ecotypes have been found, one favoring growth in fellfields and the other favoring growth in snowbeds. This ecotype divergence has occurred independently in at least two geographically separated mountain areas in Japan (Hokkaido and Tohoku), and the different ecotypes in the same region are genetically close. This pattern is similar to the results of this study. Thus, the independent divergence of floral traits can be detected by comparing floral traits and genetic structures across mountain ranges.

\section{Conclusions}

We presented evidence for convergent intraspecific floral trait evolution by showing that changes in floral morphology in populations of $L$. album var. barbatum were associated with a shift to a morphologically different pollinator assemblage, but did not reflect the degree of genetic relatedness among the L. album var. barbatum populations. This study showed that a comparative approach to plant traits and genetic structure between mountain areas can be useful for demonstrating intraspecific genetic divergence and convergence of plant traits. To verify the Grant-Stebbins model, described in the introduction, it will be necessary in the future to examine a larger clade with more transitions in pollinating systems together with information on pollinator ranges, plant migration patterns (biogeography), and the direction of pollination system transitions [39].

\section{Methods}

\section{Plant species}

Lamium album L. var. barbatum (Lamiaceae) is a perennial herb that grows along forest edges throughout East Asia [48]. It produces creamy white, two-lipped, entomophilous, and self-incompatible flowers $[40,41]$. The flowers are frequently visited by various bumblebee species, and in Japan, bumblebees are their main pollinators [41]. Flower-pollinator morphological matching has been reported to improve seed set in a population of L. album var. barbatum located near the populations of this study [42]. A bumblebee visiting a flower of $L$. album var. barbatum inserts its tongue into the inner part of the corolla tube to forage for nectar and in the process rubs its head and thorax against the anthers and the stigma. In addition to bumblebees, honeybees and wild bees have been observed to visit European (Poland) L. album flowers [40]. 


\section{Study site}

Populations of L. album var. barbatum were surveyed at 12 sites in two mountain areas in Matusmoto, Nagano Prefecture, the central Japan Alps. All surveys were conducted between April and July, during the flowering season of each population, in 2018 or 2019. The two mountain areas were around Mt. Norikura, west of the Matsumoto basin (the "west area"), and around the Utsukushigahara highland, which is east of the basin (the "east area") (Fig. 3). Each population of L. album var. barbatum was a geographically cohesive group of densely distributed plants located along a forest road in deciduous broad-leaved forest. The distance between the populations ranged from 0.4 to $52.4 \mathrm{~km}$. We conducted the following measurements during the flowering peak of each population.

\section{Floral size measurement}

First, 18-170 individuals from each population were haphazardly selected and marked with color tape. Then, following the method of Hattori et al. (2015) [41], we measured the floral size of 1-6 flowers per individual plant with a digital caliper (precision, $0.01 \mathrm{~mm}$ ). The floral size was defined as the distance from the flower's base at the stem to its tip (Fig. 4). Preliminary measurements showed that the variation of floral size among flowers on an individual plant was less than the variation among plants. Therefore, we used the average value of the measured floral sizes of 1-6 flowers on an individual plant as the floral size of that plant. We also measured plant height, as a proxy for plant resource status, of 20 haphazardly selected individuals in each population. Average floral sizes were compared between populations by using Tukey's honestly significant difference (HSD) test. In addition, we used the Moran's I test for spatial autocorrelation to determine to what degree correlations could be explained by the sampling of populations in close proximity to one another. For this test, we used the moran.test function in the "spdep" package in the $\mathrm{R}$ software environment ver. 4.0.2 [49].

\section{Pollinator assemblages and size variation}

To observe the pollinator assemblages of L. album var. barbatum, we selected the largest patch of plants (ranging in area from about 10 to $200 \mathrm{~m}^{2}$ ) in each of the 12 populations and haphazardly established a $1 \mathrm{~m} \times 1 \mathrm{~m}$ quadrat (about 100 individuals) within the patch on each census day (Table 1). We then recorded the insects that visited the flowers in this quadrat. Observations were made on several days between 8:00 and 14:00 local time, when flower visitors were active in each population. At each location, we observed all flower visitors for a total of 90-660 min spread over 1-4 days during the peak flowering period. Since bumblebee species (Bombus spp.) can be easily distinguished while they are visiting a flower, the species of each bumblebee was recorded as they visited a flower, and the observed species were recorded. In contrast, it is difficult to distinguish among Eucera spp. and species of small bees during their flower visits, so we estimated the species-level pollinator assemblage of these taxa from capture survey results (see below).

To define the size of each pollinator species, we measured morphological traits of each species relevant to the pollinating behavior of that species. For this survey, flower-visiting insects were haphazardly captured following their flower visitation, and the size of each of the selected traits was measured with a digital caliper (precision, $0.01 \mathrm{~mm}$ ). Bombus spp., Eucera spp., and Apis cerana japonica (hereafter, "large bees") are "thrust pollinators"; they forage for nectar by thrusting their heads into flowers and extending their tongues. Thus, we defined the pollinator size of large bees as the sum of the tongue length and the head length. (Fig. 4). In contrast, Ceratina spp., Lasioglossum spp., and Andrena spp. (hereafter, "small bees") are "whole-body pollinators"; they forage for nectar by crawling into the corolla tube. The small bees first land at the entrance to the flowers (upper or lower lip), and then crawl into the flowers to forage, moving through the anthers and stigma to the nectary. As a result, pollen grains become attached to both the head and the ventral side of the abdomen of small bees; thus, we defined the pollinator size of small bees as the body length from the tip of its tongue to the caudal end of the abdomen (Fig. 4). Nectar robbers (Apis mellifera, Bombus hypocrita, Xylocopa appendiculata circumvolans) and small bees on which we did not observed attached pollen grains (Euodynerus nipanicus, Lasioglossum nipponense, L. occidens, Nomada comparata at Onosawa, Nomada spp. at Onosawa) were excluded from this calculation of average pollinator size. We checked for attached pollen grains soon after a bee's visit to a flower and

(See figure on next page.)

Fig. 3 Study sites and mean floral size in each population. Distribution of floral size in the 12 populations (top) and the locations of the studied $L$. album var. barbatum populations (bottom). The vertical gray line in each histogram indicates the average floral size in that population. The size of the circles on the map indicates the average floral size of the indicated population. The west area comprises populations in the Mt. Norikura region, and the east area comprises populations in the Utsukushigahara highland region. This map is based on the Digital Topographic Map published by Geospatial Information Authority of Japan (https://www.gsi.go.jp/) 

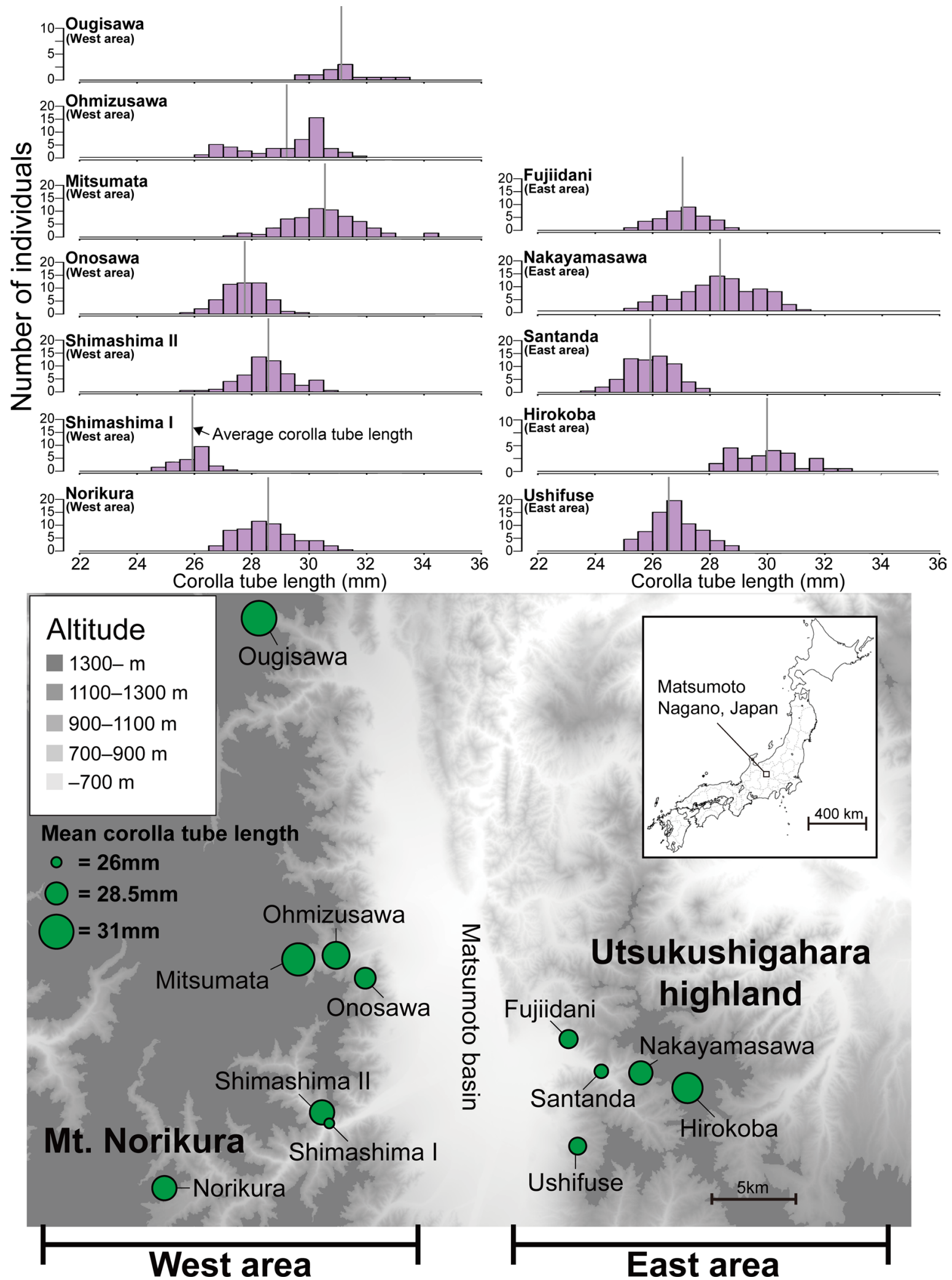


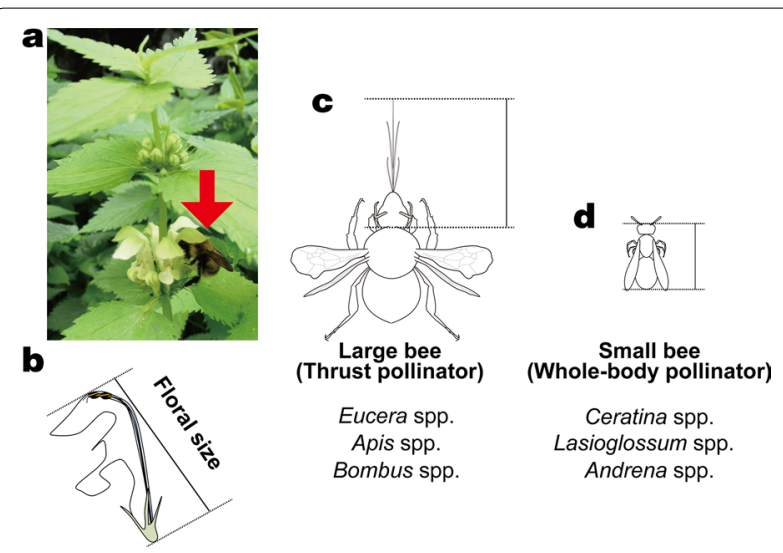

Fig. 4 Lamium album var. barbatum flowers and pollinators. a A Bombus consobrinus queen (red arrow) visiting a L. album var. barbatum flower in the Mitsumata population. $\mathbf{b}$ Measurement of floral size. c Mouthpart measurement in large bees that forage for nectar by thrusting their head into the flowers. $\mathbf{d}$ Measurement of body size of small bees that forage for nectar by crawling into the flowers

identified L. album var. barbatum pollen grains under a microscope $(\times 2-10)$. The bees were observed in a motionless state after anesthesia. Pollen grains were observed by visual inspection, and the pollen grains of $L$. album var. barbatum had a very distinct color against the body color of the bees. Pollinator size was measured separately for each plant population, even for insects of the same species. Although $B$. diversus workers were observed in the quadrat surveys at Onosawa and Norikura, and B. honshuensis workers at Ohmizusawa, they were not captured and their sizes in those populations were not measured. Therefore, the mean size of all $B$. diversus (B. honshuensis) individuals captured from the other populations was used as the size of $B$. diversus at Onosawa and Norikura (B. honshuensis at Ohmizusawa).

As the average pollinator size for each plant population, the weighted arithmetic mean was calculated from the relative abundance of each pollinator species in the pollinator assemblage and the size of that species:

$$
\text { Averagepollinatorsize }=\sum_{\mathrm{i}=1}^{\mathrm{n}} \mathrm{Pi}(\mathrm{Ni} / \mathrm{Nt})
$$

where $n=$ the total number of insect species visiting a L. album var. barbatum population (patch), $P i=$ mean size of the $i$ th insect species, $N i=$ the number of flowers in the patch that the $i$ th insect species visited, and $N t=$ the number of flowers in the patch that any of the insect species visited. Thus, $N i / N t$ is the relative abundance of the $i$ th insect species visiting the population.
For each population, average pollinator size was calculated for three groups of flower visitors: all flower visitors, only large bees, and only small bees.

\section{Factors influencing local floral size}

To examine factors influencing floral size, we used a linear mixed model (LMM) with a Gaussian error distribution and identity as the link function. Before this analysis, we tested the effect of the variables by likelihood ratio tests. First, we prepared a model with all variables as follows: floral size of each individuals was the response variable, and the average pollinator size (all pollinators), average pollinator size (only large bees), average pollinator size (only small bees), average plant height of each population, and the altitude of each population were predictive variables. We treated the altitude as a proxy for clinal abiotic environmental changes (e.g. meteorological changes). In addition, we treated plant individual and sampling data (year and month) as random effects. The variance inflation factor (VIF) statistic was used to confirm the correlation among predictive variables with $\mathrm{VIF}=0.5$ as a threshold value [50]. No VIFs above the threshold were detected. A likelihood ratio test using the parametric bootstrap method [51] was performed for models that included all variables and models that lacked one of each predictive variable and random effect. Variables were selected from the difference in deviance between the models obtained by 1000 bootstrap calculations. As a likelihood ratio test results, the average pollinator size (all pollinators), average pollinator size (only large bees) and altitude remained as predictive variables.

The LMM analysis was performed with the lmer function in the "lme4" package in the $\mathrm{R}$ software environment ver. 4.0.2 [49]. We further conducted a model selection approach based on AIC. First, we performed model selection on the entire dataset using brute force approach (trying every possible model), starting from a global model including all remained predictive variable by likelihood ratio test, and plant individual and sampling data (year and month) as random effects. These are the explanatory variables that were judged to be valid in the likelihood ratio test results. We then compared the global model with all simpler models based on AIC (i.e. comparing all the combinations of explanatory variables) using the dredge function in the "MuMIn" package in the R software environment ver. 4.0.2 [49]. This function returned the model with the lowest Akaike information criterion (AIC), and we adopted this model (Additional file 2: Table S2). The results of this model selection procedure informed which average pollinator size variable (all pollinators or only large bees) was used in a least-squares regression analysis. Using these results, therefore, we 
explored covariation between corolla tube length and the average pollinator size of only large bees across populations by a least-squares regression analysis.

\section{Genetic similarities of Lamium album var. barbatum populations}

To examine the genetic structure of L. album var. barbatum, we used 10 polymorphic microsatellite primers originally developed for L. album [52] (Additional file 4: Table S3). For this analysis, fresh leaf material was collected randomly from 8-16 individual plants in each of the 12 L. album var. barbatum populations during 20182019. DNA was extracted by the CTAB method [53], and the extracted DNA was diluted or concentrated to a final concentration of $10 \mu \mathrm{g} / \mathrm{ml}$.

Each of the forward microsatellite primers was synthesized after adding one of four different universal fluorescent sequences: 5'-GCCTCCCTCGCGCCA-3', 5'-GCC TTGCCAGCCCGC-3', 5'-CAGGACCAGGCTACC GTG-3', or 5'-CGGAGAGCCGAGAGGTG-3' [54]. Polymerase chain reaction (PCR) analyses were performed in a thermal cycler using a reaction mixture consisting of $1 \mu \mathrm{l}$ template DNA, $3 \mu \mathrm{l}$ of $2 \times$ Type-it Microsatellite PCR Kit (QIAGEN, Valencia, California, USA), $0.7 \mu \mathrm{l}$ of $0.1 \mu \mathrm{M}$ forward primer, $0.7 \mu \mathrm{l}$ of $0.2 \mu \mathrm{M}$ reverse primer, and $0.7 \mu \mathrm{l}$ of $0.1 \mu \mathrm{M}$ fluorescent-labeled universal primer. The DNA amplification program consisted of an initial denaturation step of $5 \mathrm{~min}$ at $95^{\circ} \mathrm{C}$, followed by 35 cycles at $95^{\circ} \mathrm{C}$ for $30 \mathrm{~s}, 60^{\circ} \mathrm{C}$ for $90 \mathrm{~s}$, and $72^{\circ} \mathrm{C}$ for $30 \mathrm{~s}$, and final elongation at $60{ }^{\circ} \mathrm{C}$ for $30 \mathrm{~min}$. The PCR products were detected by using an ABI Prism 3130 Genetic Analyzer (Applied Biosystems, Waltham, Massachusetts, USA) and GeneScan ${ }^{\mathrm{TM}} 500 \mathrm{LIZ}^{\mathrm{TM}}$ dye Size Standard (Applied Biosystems). Fragment lengths were calculated with GeneMapper version 4.0 software (Applied Biosystems).

We tested two analysis of molecular variance (AMOVA) models estimating the percentage of molecular variance accounted for by each level of the nested sampling hierarchy. First model, 12 populations were divided according to the two mountain areas (east or west areas). Second model, 12 populations were divided the six floral size groups. Floral size groups were constructed based on the results of Tuley's HSD comparison of the average floral size among the populations. Floral size groups were divided into six groups with significantly different flower sizes (see Table 1, alphabet a, b, c, $\mathrm{d}$, e, fg). AMOVA was run using Arlequin ver 3.5.2.2 [55]. The significance of variance components in the AMOVA models was tested by 1000 random permutations.

In addition, a Bayesian clustering analysis of the fragment length datasets was performed with STRUCTURE software version 2.3.4 [56, 57]. We used this analysis to determine the genetic cluster to which each individual is assigned. Simulations were conducted with $100 \mathrm{k}$ burn-in iterations and $100 \mathrm{k}$ Markov chain Monte Carlo repetitions. The number of genetic clusters $(K)$ was calculated 10 times for each of $1-12$, and the $\Delta K$ value [58] was used as the criterion for selecting the appropriate number of clusters, that is, the number of genetic clusters from which the 12 populations of L. album var. barbatum were derived.

\section{Supplementary Information}

The online version contains supplementary material available at https://doi. org/10.1186/s12862-021-01796-8.

Additional file 1: Table S1. Sizes of the captured flower visitors (pollinators) in each population (mean \pm SE). Insects using the "whole-body" visitation mode are small bees, and those using the "thrust" visitation mode are large bees (See Table 1). Castes of Bombus spp. are indicated by W, worker, or Q, queen. An asterisk following the species name indicates that no pollen grains were found on the bodies of insects of that species.

Additional file 2: Table S2. Results of the LMM model selection using the dredge function in the "MuMIn" package.

Additional file 3: Figure S1. Geographic genetic structure on study sites. Pie chart indicate that the proportion of the two clusters identified by STRUCTURE as averaged for each population. The west area comprises populations in the Mt. Norikura region, and the east area comprises populations in the Utsukushigahara highland region.

Additional file 4: Table S3. Information on the 10 microsatellite markers used in this study. These markers were developed by Horsley (2013) [52].

\section{Acknowledgements}

We thank S. Duhon for English editing. We thank the Chubu District Forest Office (Forestry Agency), the Chubu Regional Office for Nature Conservation (Ministry of the Environment), and the Matsumoto Regional Office (Nagano Prefectural Government) for permission to work in the area. This study was supported by the Ministry of Education, Culture, Sports, Science and Technology of Japan (MEXT) $(15 \mathrm{H} 02641,19 \mathrm{H} 03300,19 \mathrm{~J} 22443)$ and the fund of Nagano Prefecture to promote scientific activity.

\section{Authors' contributions}

T. Toji, M. Hattori, and T. Itino conceived the ideas and wrote the manuscript. T. Toji and N. Ishimoto collected field data. T. Toji and S. Egawa conducted the molecular biology experiments and analysis. Y. Nakase provided support in the statistical analysis and helped with insect species identification. All authors read and approved the final manuscript.

\section{Availability of data and materials}

The datasets used and/or analysed during the current study available from the corresponding author on reasonable request.

\section{Declarations}

Ethics approval and consent to participate

Not applicable.

\section{Consent for publication}

Not applicable.

\section{Competing interests}

The authors declare that they have no competing interests.

\section{Author details}

${ }^{1}$ Graduate School of Medicine, Science and Technology, Shinshu University, Matsumoto, 3-1-1 Asahi, Nagano 390-8621, Japan. Faculty of Science, Shinshu 
University, Matsumoto, 3-1-1 Asahi, Nagano 390-8621, Japan. ${ }^{3}$ Graduate School of Fisheries and Environmental Sciences, Nagasaki University, 1-14 Bunkyo-machi, Nagasaki 852-8521, Japan. ${ }^{4}$ Department of Biology and Institute of Mountain Science, Shinshu University, Matsumoto, 3-1-1 Asahi, Nagano 390-8621, Japan.

Received: 28 January 2021 Accepted: 15 April 2021 Published online: 24 April 2021

\section{References}

1. Galen C. Rates of floral evolution: adaptation to bumblebee pollination in an alpine wildflower. Polemonium Viscosum Evolution. 1996;50:120-5.

2. Scobell SA, Scott PE. Visitors and floral traits of a hummingbird-adapted cactus (Echinocereus coccineus) show only minor variation along an elevational gradient. Am Midl Nat. 2002;147(1):1-15.

3. Dohzono K, Suzuki K, Murata J. Temporal changes in calyx tube length of Clematis stans (Ranunculaceae): a strategy for pollination by two bumble bee species with different proboscis lengths. Am J Bot. 2004;91:2051-9.

4. Herrera CM, Castellanos MC, Medrano M. Geographical context of floral evolution: towards an improved research programme in floral diversification. In: Harder LD, Barrett SCH, editors. Ecology and evolution of flowers. Oxford: Oxford University Press; 2006.

5. Inoue MN, Ushijima J, Yokoyama J. Effect of Weigela hortensis (Caprifoliaceae) floral morphology on pollinator behavior. Plant Species Biol. 2007;22:77-86.

6. Gómez J, Perfectti F, Bosch J, Camacho J. A geographic selection mosaic in a generalized plant-pollinator-herbivore system. Ecol Monogr. 2009;79:245-63.

7. Nattero J, Malerba R, Medel R, Cocucci A. Factors affecting pollinator movement and plant fitness in a specialized pollination system. Plant Syst Evol. 2011;296:77-85.

8. Grant V, Grant KA. Flower pollination in the Phlox family. New York: Columbia University Press; 1965.

9. Stebbins GL. Adaptive radiation of reproductive characteristics in angiosperms, I: pollination mechanisms. Annu Rev Ecol Syst. 1970;1:307-26.

10. Galen C, Newport M. Bumble bee behavior and selection on flower size in the sky pilot, Polemonium viscosum. Oecologia. 1987;74:20-3.

11. Johnson SD. The pollination niche and its role in the diversification and maintenance of the southern African flora. Phil Trans R Soc Lond B. 2010;365:499-516.

12. Gómez JM, Perfectti F, Camacho JPM. Natural selection on Erysimum mediohispanicum flower shape: insights into the evolution of zygomorphy. Am Nat. 2006;168:531-45.

13. Nagano Y, Abe K, Kitazawa T, Hattori M, Hirao AS, Itino T. Changes in pollinator fauna affect altitudinal variation of floral size in a bumblebeepollinated herb. Ecol Evol. 2014;4:3395-407.

14. Hodges S. A rapid adaptive radiation via a key innovation in Aquilegia. In: Givnish TJ, Sytsma KJ, editors. Molecular evolution and adaptive radiation. Cambridge: Cambridge University Press; 1997. p. 391-405.

15. Fenster CB, Armbruster WS, Wilson P, Dudash MR, Thomson JD. Pollination syndromes and floral specialization. Annu Rev Ecol Evol Syst. 2004;35:375-403.

16. Campbell DR, Waser NM, MelendezAckerman EJ. Analyzing pollinatormediated selection in a plant hybrid zone: Hummingbird visitation patterns on three spatial scales. Am Nat. 1997;149:295-315.

17. Newman E, Anderson B, Johnson SD. Flower colour adaptation in a mimetic orchid. Proc R Soc B-Biol Sci. 2012;279:2309-13.

18. Pellmyr O. Three pollination morphs in Cimicifuga simplex; incipient speciation due to inferiority in competition. Oecologia. 1986;68:304-7.

19. Majetic CJ, Raguso RA, Ashman TL. The sweet smell of success: floral scent affects pollinator attraction and seed fitness in Hesperis matronalis. Funct Ecol. 2009;23:480-7.

20. Steiner KE, Whitehead V. Oil flowers and oil bees: further evidence for pollinator adaptation. Evolution. 1991;45:1493-501.

21. Alexandersson R, Johnson SD. Pollinator-mediated selection on flowertube length in a hawkmoth-pollinated Gladiolus (Iridaceae). Proc R Soc B-Biol Sci. 2002;269:631-6.

22. Anderson B, Johnson SD. The geographical mosaic of coevolution in a plant-pollinator mutualism. Evolution. 2008;62:220-5.
23. Anderson B, Johnson SD. Geographical covariation and local convergence of flower depth in a guild of fly-pollinated plants. New Phytol. 2009;182:533-40.

24. Gómez JM, Abdelaziz M, Camacho JPM, Muñoz-Pajares AJ, Perfectti F. Local adaptation and maladaptation to pollinators in a generalist geographic mosaic. Ecol Lett. 2009;12:672-82.

25. Pauw A, Stofberg J, Waterman RJ. Flies and flowers in Darwin's race. Evolution. 2009;63:268-79.

26. Anderson B, Alexandersson R, Johnson SD. Evolution and coexistence of pollination ecotypes in an African Gladiolus (Iridaceae). Evolution. 2010;64:960-72.

27. Dohzono I, Suzuki K. Morphological and genetic differentiation in /sodon umbrosus by altitudinal variation in bumblebee pollinator assemblages. Plant Species Biol. 2010;25:20-9.

28. Johnson SD, Anderson B. Coevolution between food-rewarding flowers and their pollinators. Evol Educ Outreach. 2010;3:32-9.

29. Thompson JN, Schwind C, Guimarães PR, Friberg M. Diversification through multitrait evolution in a coevolving interaction. Proc Natl Acad Sci. 2013;110:11487-92.

30. Boberg E, Alexandersson R, Jonsson M, Maad J, Agren J, Nilsson LA. Pollinator shifts and the evolution of spur length in the moth-pollinated orchid Platanthera bifolia. Ann Bot. 2014;113:267-75.

31. Kuriya S, Hattori M, Nagano Y, Itino T. Altitudinal flower size variation correlates with local pollinator size in a bumblebee-pollinated herb, Prunella vulgaris L. (Lamiaceae). J Evol Biol. 2015;28:1761-9.

32. Egawa S, Hirose K, Itino T. Geographic changes in pollinator species composition affect the corolla tube length of self-heal (Prunella vulgaris L.): evidence from three elevational gradients. Ecol Res. 2020;35:819-25.

33. Newman E, Manning J, Anderson B. Local adaptation: Mechanical fit between floral ecotypes of Nerine humilis (Amaryllidaceae) and pollinator communities. Evolution. 2015;69:2262-75.

34. Anderson B, Ros P, Wiese TJ, Ellis AG. Intraspecific divergence and convergence of floral tube length in specialized pollination interactions. Proc $R$ Soc B-Biol Sci. 2014;281:20141420.

35. Van der Niet T, Johnson SD. Phylogenetic evidence for pollinator-driven diversification of angiosperms. Trends Ecol Evol. 2012;27:353-61.

36. Thompson JN. The geographic mosaic of coevolution. Chicago: University of Chicago Press; 2005.

37. Thompson JN. Relentless evolution. Chicago: University of Chicago Press; 2013.

38. Briscoe Runquist RD, Moeller DA. Floral and mating system divergence in secondary sympatry: testing an alternative hypothesis to reinforcement in Clarkia. Ann Bot. 2014;113:223-35.

39. Van der Niet T, Pirie MD, Shuttleworth A, Johnson SD, Midgley JJ. Do pollinator distributions underlie the evolution of pollination ecotypes in the Cape shrub Erica plukenetii? Ann Bot. 2014;113:301-15.

40. Sulborska A, Dmitruk M, Konarska A, Weryszko-Chmielewska E. Adaptation of Lamium album L. flowers to pollination by Apoidea. Acta Scientiarum Polonorum-Hortorum Cultus. 2014;13:31-43.

41. Hattori M, Nagano Y, Itino T. Geographic variation in flower size and flower-visitor composition of two bumblebee-pollinated, spring-flowering herbs, Lamium album L. var. barbatum (Lamiaceae) and Meehania urticifolia (Lamiaceae). Am J Plant Sci. 2015;6:737-45.

42. Hattori M, Tamada Y, Itino T. Effect of pollinator size on seed set in Lamium album L. var. barbatum. Plant Ecol Evol. 2021. (in press).

43. Suzuki K, Dohzono I, Hiei K. Evolution of pollinator generalization in bumblebee-pollinated plants. Plant Species Biol. 2007;22:141-59.

44. Wade MJ, Kalisz S. The causes of natural selection. Evolution. 1990;44:1947-55.

45. Paterno GB, Silveira CL, Kollmann J, Westoby M, Fonseca CR. The maleness of larger angiosperm flowers. Proc Natl Acad Sci. 2020;117(20):10921-6.

46. Toji T, Itino T. Differences in sex expression and mating systems in three pollination morphs of Cimicifuga simplex. Plant Species Biol. 2020;35:112-9.

47. Hirao AS, Shimono Y, Narita K, Wada N, Kudo G. Ecotypic divergences of the alpine herb Potentilla matsumurae adapted to fellfield-snowbed habitats across a series of mountain sky islands. Am J Bot. 2019;106:772-87.

48. Hayashi Y. Nihon-no Yasou. Tokyo: Yama to Keikoku Sha; 2009.

49. Team RC. R: A language and environment for statistical computing. Vienna: R Foundation for Statistical Computing; 2015. 
50. Neter J, Kutner MH, Nachtsheim CJ, Wasserman W. Applied linear statistical models. Chicago: Irwin; 1996.

51. Hoel PG, Port SC, Stone CJ. Introduction to statistical theory. Boston: Houghton Mflin Company; 1971.

52. Horsley CA. Pollinator-mediated interactions between native plants and the invasive alien Himalayan balsam. Leeds: University of Leeds; 2013.

53. Doyle JJ, Doyle JL. Isolation ofplant DNA from fresh tissue. Focus. 1990;12:39-40.

54. Blacket MJ, Robin C, Good RT, Lee SF, Miller AD. Universal primers for fluorescent labelling of PCR fragments-an efficient and costeffective approach to genotyping by fluorescence. Mol Ecol Resour. 2012;12:456-63

55. Excoffier $L$, Lischer HE. Arlequin suite ver. 35: a new series of programs to perform population genetics analyses under Linux and Windows. Mol Ecol Resour. 2010;10:564.
56. Pritchard JK, Stephens M, Donnelly P. Inference of population structure using multilocus genotype data. Genetics. 2000;155:945-59.

57. Falush D, Stephens M, Pritchard JK. Inference of population structure using multilocus genotype data: linked loci and correlated allele frequencies. Genetics. 2003;164:1567-87.

58. Evanno G, Regnaut S, Goudet J. Detecting the number of clusters of individuals using the software STRUCTURE: a simulation study. Mol Ecol. 2005;14:2611-20.

\section{Publisher's Note}

Springer Nature remains neutral with regard to jurisdictional claims in published maps and institutional affiliations.
Ready to submit your research? Choose BMC and benefit from:

- fast, convenient online submission

- thorough peer review by experienced researchers in your field

- rapid publication on acceptance

- support for research data, including large and complex data types

- gold Open Access which fosters wider collaboration and increased citations

- maximum visibility for your research: over 100M website views per year

At BMC, research is always in progress.

Learn more biomedcentral.com/submissions 